This article deals some issues about history of tele-education in Brazil. Some significant programs and experiments that came along with modern media evolution are mentionated. Other experiences were left out, even so these also contributed to the distance education evolution in Brazil. It was done that way in order to select educative experiences that uses teaching technologies to take place.

Keywords: history, tele-education, Brasil 


\section{Uma história da educação a distância}

\section{Leci Maria de Castro Augusto}

COSTA

...a história do mundo vivo se resume de olhos cada vez mais perfeitos no seio de um Cosmos, onde é possível ver cada vez mais.

Teilhard de Chardin, O fenmeno humano.

Esse artigo trata de alguns tópicos sobre a histórica da Educação a Distância no Brasil. Priorizou-se, nesse perfil, alguns programas e experiências significativas relacionados à evolução das diversas mídias empregadas, deixando de citar alguns programas desenvolvidos nessa área, ainda que, possivelmente, tenham contribuído para a evolução da EAD no Brasil. Eleger-se-ão algumas experiências educativas com uso de tecnologias para ensino.

Palavras-chave-: história, tele-educação, Brasil 


\section{Evocando as raízes}

Poder-se-ia remeter a EAD a qualquer modalidade de transmissão e/ou construção de conhecimento, sem a presença simultânea dos protagonistas, por estarem separados, no tempo e no espaço físico, e, juntos, na ação educativa. A difusão da escrita, tem sido considerada um marco que relaciona o desenvolvimento histórico da educação ao meio tecnológico utilizado na comunicação. A escrita e o processo de reprodução dos livros tornaram-se fatores de extrema eficácia para a educação, utilizados até hoje.

Eduardo Chaves (1999) ressalva que a invenção da escrita possibilitou que as pessoas escrevessem o que antes só podiam dizer e, assim, permitiu o surgimento da primeira forma de EAD: o ensino por correspondência, para o autor, as epístolas do Novo Testamento (destinadas a comunidades inteiras), que possuem nítido caráter didático, são claros exemplos de EAD.

Chaves, em editorial da revista A Tecnologia na educao. Uma perspectiva da Microsoft, comenta que o escritor Peter Drucker, em seu livro Novas Realidades, anuncia uma segunda Renascença, que também teve como força motriz uma tecnologia educacional: o computador. "O computador, que nasceu como tecnologia bélica, e se popularizou como tecnologia industrial e comercial, é hoje, eminentemente, meio de comunicação e tecnologia educacional", como foi o livro na primeira Renascença, em 1450, gerando a democratização do conhecimento e meio de comunicação.

João Roberto Moreira Alves (2007) também entende que o surgimento da EAD no mundo remonta ao século $X V$, com a invenção da imprensa, na Alemanha, por Johannes Gutemberg, utilizando caracteres móveis. Alves afirma que, com a criação do livro impresso, deixou de ser necessário freqüentar a escola para ouvir o mestre ler os raros livros copiados à mão.

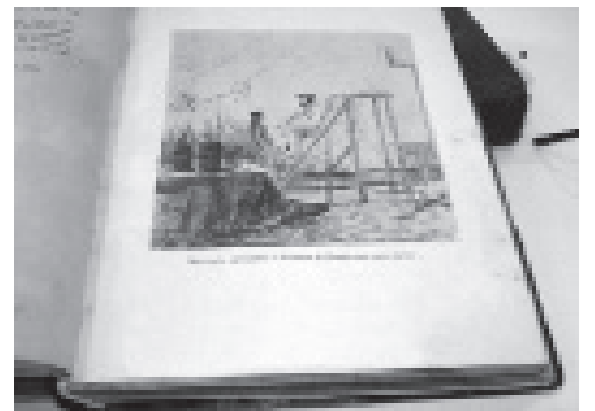

Augusto, livro Antonio Parreiras Fotografia, 2006 
As primeiras experiências registradas em EAD datam de 1883, na Suécia, em 1840, na Inglaterra e, por volta de 1856, na Alemanha e nos Estados Unidos. O ensino por correspondência surge em 1874 e, no Brasil, a EAD surgiu, provavelmente, em 1904, com os cursos das "Escolas Internacionais". No entanto, segundo o autor, houve uma publicação no Jornal do Brasil, edição de 1891, que registrou, na seção de classificados, anúncio de oferta de curso profissionalizante de datilografia, por correspondência.

Atualmente, existe EAD em quase todo o mundo. Os grandes centros de difusão de pesquisas estão na França, na Espanha e na Inglaterra, contribuindo para o desenvolvimento da EAD em diversos países, com modelos desenvolvidos no Centre Nacional de Educacin a Enseigmente a Distance e pela Open University. Ainda se destacam, neste campo de pesquisa, na América Latina, a Venezuela, Universidade Nacional Abierta, Costa Rica e, recentemente na América do Norte, o Canadá, por meio da tel-Universit.

De acordo com Maria de Fátima Guerra de Sousa e Ivônio Nunes (2000), no século XX, com a Segunda Guerra Mundial, foi possível o desenvolvimento de algumas experiências aplicadas ao ensino por correspondência, principalmente pela necessidade de programas de treinamento e capacitação que utilizavam técnicas de EAD.

Para Kleber Mundin (2006), a EAD evoluiu historicamente através das diferentes gerações do desenvolvimento das telecomunicações, principalmente da informática e da internet. De acordo com o autor, essa evolução pode ser agrupada em quatro diferentes gerações, a saber: a primeira geração (18401970) diz respeito aos cursos por correspondência, que eram realizados em casa, a partir de materiais didáticos, produzidos pelos instrutores, como ocorreu na Europa e nos Estados Unidos, e enviados por serviços postais; a segunda geração (19701980) ficou caracterizada pela uso do rádio e da televisão como complementos do material enviado por correspondência; a terceira geração (1980-1990) caracteriza-se pelo uso da transmissão por satélite, destacando-se o papel da TV e do vídeo e, na quarta geração (1990-), ressalta-se o uso das novas tecnologias 
de comunicação (internet, computador).

\section{Memória nacional}

Acordando com a sistematização proposta por Mundin (2006), registra-se que essa evolução da EAD no Brasil e no mundo passou pelas seguintes fases: a fase do ensino por correspondência; a da transmissão radiofônica; em seguida, a televisiva; assim, o uso da informática foi se disseminando nos programas de EAD até os dias de hoje, com a utilização conjugada de meios - a telemática e a multimídia. Ressalta-se que o caráter profissionalizante marcou as escolas por correspondência até o início do século XX, e cursos como o de datilografia e o de rádio técnico eram oferecidos, por meio de anúncios em revistas e jornais. Enfatiza-se, nesse caso, o Instituto Rádio Técnico Monitor, com fundação em 1939, e, em 1941, surge o Instituto Universal Brasileiro (SOUSA \& NUNES, 2000).

Até a metade do século $X X$, muitas outras entidades da iniciativa privada desenvolveram cursos profissionalizantes de nível médio e elementar, cursos bíblicos, de eletrônica, datilografia, etc. O Serviço Nacional de Aprendizagem Comercial (SENAC) surgiu em 1946, com sede no Rio de Janeiro e em São Paulo, oferecendo cursos por correspondência.

No Brasil, o primeiro projeto relevante da segunda fase foi a criação da Rádio Sociedade do Rio de Janeiro (mais tarde foi denominada de Rádio MEC), em 1923, idealizada por Henrique Morezi e Roquet Pinto. O objetivo da emissora era promover a educação pelo rádio. Em 1936, essa emissora foi doada ao Ministério da Educação e Saúde e, em 1937, foi criado o Serviço de Radiodifusão Educativo do Ministério de Educação.

De acordo com Alves (2007), a instituição, em 1950, atingia 318 localidades, oferecendo cursos profissionalizantes.

Em 1958, entre outras experiências com o uso do rádio, destaca-se a experiência pioneira da diocese de Natal, surge o Movimento de Educação de Base (MEB), que foi criado a partir de um convênio entre a Conferência Nacional dos Bispos do Brasil (CNBB) e o Ministério da Educação. Para Sousa e Nunes (2000), o programa estava voltado para a alfabetização e o acompanhamento dos primeiros passos dos milhares de jovens 
e adultos, e teve como referência uma experiência da Rádio Sutalenza, da Colômbia. O movimento agregou capitais do Nordeste, Norte e Centro-Oeste em experiências de educação popular, com a utilização do rádio, com preparação de material impresso, pela mobilização social e valorização da cultura em encontros comunitários, congressos e festas populares.

Após o Golpe Militar de1964, o MEB foi reprimido e as atividades interrompidas. Porém, as "escolas radiofônicas", desenvolvidas a partir desse Movimento, notadamente no Norte e Nordeste do país, foram, sem dúvida, um dos importantes projetos de EAD no Brasil, articulando as classes populares.

Na década de 70, a partir de um acordo entre o Ministério de Educação e o Ministério das Comunicações, o Governo Federal iniciou o Projeto Minerva, cujo nome remete à deusa grega da sabedoria. Foi um programa radiofônico de trinta minutos de duração, com transmissão em cadeia nacional, de cunho informativo-cultural e educativo. A transmissão foi obrigatória para todas as emissoras do país, e o projeto objetivava "propor uma alternativa ao sistema tradicional de ensino como formação suplementária à educação continuada" (ALONSO apud SOUSA \& NUNES, 2000, p. 53).

A produção foi regionalizada e ficou a cargo da Fundação Educacional Padre Landell de Moura (FEPLAM), no Rio Grande do Sul, e à Fundação Padre Anchieta, em São Paulo, coube a responsabilidade da distribuição. O projeto foi composto por diversos cursos (capacitação para o ginásio, composto com 100 aulas, o de madureza ginasial, com 450 aulas, entre outros cursos, além de uma série de programas de atualização e de informação). No entanto, não respondia à diversidade cultural brasileira (costumes, sotaques, modo de vida) e nem às necessidades e interesses das diferentes regiões do país. A experiência, apesar de inovadora, foi negativa, reflexo da baixa audiência nos cursos e do distanciamento da produção em relação à diversidade cultural nacional.

Atualmente, o rádio ainda é uma mídia importante e encontra-se em funcionamento o Programa Rádio Escola, da Secretaria de Educação a Distância (SEED), do Ministério de Educação, que tem como objetivo desenvolver ações para escolas públicas 
ou junto às comunidades, visando à utilização da linguagem radiofônica (bem como a mobilização dessa mídia) na difusão e no desenvolvimento de práticas pedagógicas, além de fornecer insumos para o exercício docente. Esse programa é desenvolvido pelo Núcleo de Comunicação e Educação da Escola de Educação e Artes da USP e envolve o conceito da educomunicao, que propõe a construção de ecossistemas comunicativos abertos, dialógicos e criativos, nos espaços educativo e social. $\mathrm{O}$ projeto atende à Região Centro-Oeste e tem como objetivo desenvolver a educação tecnológica, a leitura crítica do meio e o domínio da ferramenta como objeto de expressão e produção cultural. O programa também disponibiliza material para alfabetização de jovens e adultos.

Cada escola participante, nos estados, recebe um kit de equipamentos, que inclui microfones, aparelhos de CD e fita K7, mesa de som de 8 canais, transmissor, antena e duas caixas receptoras sem fio, que podem ser colocadas em qualquer parte da escola.

A partir da década de 50, percebeu-se a possibilidade da televisão se tornar um meio de comunicação importante para Educação a Distância. Do início dos anos 60 até a década de 80, vários sistemas de televisão educativa foram montados na Europa, no Japão e no Brasil. De acordo com Sousa e Nunes (2000, p. 49), por se tratar de um veículo de grande poder de sedução, pois conjuga som e imagem, "muitos desses sistemas educativos foram criados somente com base na veiculação de cursos através da própria televisão". Para os autores, a evolução desses sistemas se deu com a conjugação de outros meios, na busca de novas formas de ensino e aprendizagem. As emissoras, assim como o cinema, criaram uma forma própria de recepção.

Segundo Maria Helena Silveira (2002), nos anos de 1940 e 50, a exigência para se fazer cinema ou TV voltados para educação era ter formação em pedagogia. Na TV, a produção era muito incipiente e a concepção pedagógica dos cursos não

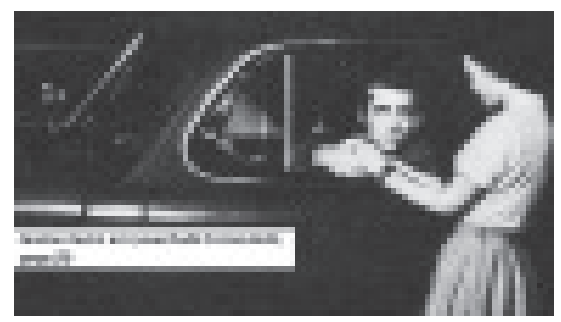


valorizava os sentidos possíveis de serem explorados pelo meio na ação educativa, permanecendo com forte apelo oral, exigindo somente da audição. Para a autora, alguns programas de TV poderiam ser transmitidos pelo rádio, dada a ênfase na oralidade da comunicação dos conteúdos. No entanto, do cinema não se pode dizer a mesma coisa. Desde as primeiras décadas do século XX, o cinema era um "evento social" que mobilizava parte da população urbana em um ritual dominical, paixão largamente difundida pela população adulta. De acordo com Guacira Lopes Louro (2000, p. 423), "o cinema era uma instância educativa potente. Poderosamente, sedutoramente, o cinema se constituía como uma nova pedagogia cultural". A popularidade do cinema permite que ele seja compreendido como instância de produção de identidade cultural na sociedade brasileira, de modo especial durante o período de 1930 a 1970. "Uma instância que participava de um processo pedagógico mais amplo; uma instância que integrava e interferia nas redes sociais de poder", (LOURO, 2000, p. 426). Na análise das produções cinematográficas da época, a autora procura demonstrar como o cinema, as produções "hollywoodiana", com ética e estética próprias, engendrou na sociedade brasileira práticas sociais, especialmente de gênero e sexual, disponibilizadas à juventude e amplamente distribuídas e consumidas em diversos países.

A televisão teve algumas experiências pioneiras em EAD, por volta dos anos 60, como o projeto Saci, que foi executado de forma experimental pelo Instituto Nacional de Pesquisa Espacial (INEP) e funcionou até os anos 70. O projeto objetivava estabelecer um sistema nacional de teleducação para treinamento de professores de ensino básico.

Atualmente, a Fundação Roberto Marinho mantém os programas Telecurso de $1^{\circ}$ e $2^{\circ}$ graus, atendendo ao ensino fundamental e médio.

Sobre o sistema de TV Educativa, são vários os estados com experiências significativas e muitos com programação própria e em funcionamento até hoje, como, por exemplo, a Fundação de Teleducação do Ceará (FUNTELC), conhecida como TVE Ceará, criada na década de 70, no processo de implantação das televisões educativas. Segundo Sousa e Nunes (2000), este 
projeto e o projeto da TV Educativa do Maranhão, desde 1974, desenvolvem uma programação de ensino regular (de $5^{\text {a }}$ a $8^{\underline{a}}$ séries do ensino fundamental), com implantação de telesalas e uma marca de cem mil alunos regulares no sistema.

O programa Salto para o Futuro, sob a coordenação de Ana Mae Barbosa, que deu enfoque às Artes Visuais, foi elaborado para aperfeiçoamento dos professores em regência, nas séries iniciais, pela Fundação Roquete Pinto (TVE/RJ), em parceria com a Secretaria Nacional de Educação Básica, articulada com as Secretarias Estaduais de Educação, no final da década de 80 e início dos anos 90. Utilizando a TV como meio de transmissão e comunicação de conhecimentos, foram organizados núcleos de recepção em escolas e universidades. Após 1997, o programa passou a integrar a grade de programação do canal da TV Escola.

A TV Escola foi criada, em 4 de setembro de 1995, com um sistema operacional em fase experimental e, depois, em definitivo, em 4 de março de 1996, pelo Ministério da Educação. De acordo com Paulo Renato de Souza (1998, p. 17), "a idéia era criar um programa, que atingisse 50 mil escolas em todo Brasil, usando o canal de satélite brasileiro para programa de treinamento de professores". A TV Escola é um projeto que objetiva capacitação, aperfeiçoamento e atualização dos professores de ensino fundamental e médio, visando à melhoria da qualidade do ensino, tendo a televisão como meio de EAD.

Em junho de 1995, por meio de Portaria no 649/95-MEC, definiu-se o que se denominou de Kit tecnolgico, contendo um vídeo cassete, uma antena parabólica, um televisor, um estabilizador de voltagem e dez fitas. Enviados para as escolas da rede pública para operacionalização do projeto, somaram cinqüenta mil kits em território brasileiro. Em outra Portaria, a de no 955/95, o MEC convidou produtoras de vídeo educativos para apresentarem seus projetos com vista a estabelecer a grade da programação, incluindo entendimentos entre técnicos do MEC e emissoras educativas da Inglaterra, do Canadá e da França.

Segundo José Roberto Sadeck (1998, p. 25), a orientação pedagógica e filosófica da TV Escola está apoiada nos Parâmetros Curriculares Nacionais e informa que "um dos diferenciais 
da nossa TV é que a estrutura de sua programação é vertical", isto significa que deve haver um aprofundamento temático ou abordagens diferenciadas sobre o mesmo tema. Ao longo destes anos de transmissão, foi possível a criação de acervos em muitas escolas.

Conforme Laura Coutinho (2003), inicialmente, a transmissão da TV Escola, se dava em base experimental, com quatro horas de programação diária, baseada em duas grandes linhas, uma de apoio ao professor na sala de aula e outra que colaborava com a formação do professor.

A autora enfatiza:

O projeto TV Escola, que é anunciado como uma janela aberta para o mundo pode-se constituir em apenas uma fresta, cada vez mais estreita, por não incorporar as dinâmicas culturais próprias em que cada escola se insere. Em nome da democratização e da igualdade de oportunidades pode estar em curso um amplo programa de massificação e homogeneização da informação, nada democrático e nada equalizador, porque desconhecedor das identidades e aspirações culturais de cada uma das regiões e comunidades escolares (COUTINHO, 2003, p. 91).

A autora alerta para uso do currículo único, sem considerar o contexto, suas especificidades e diferenças. E, ao mesmo tempo, o risco de a TV se constituir no mito da modernidade e da resolução dos problemas didático-pedagógicos.

Ademais, com o surgimento da televisão, acreditou-se na possibilidade do potencial do meio, no sentido de redução do número dos excluídos do sistema educativo presencial. No entanto, para Claudio Menezes,

A infeliz coincidência histórica - do surgimento de algumas dessas iniciativas em um ambiente mundial contaminado pela guerra fria e/ou governos ditatoriais - gerou desconfiança, muitas vezes justificadas, do uso de tais programas para veiculação da ideologia oficial, interrompendo o diálogo entre o professor e o aluno (MENEZES, 1997, p. 62).

O autor considera que a falta de interatividade do meio reforça e contribui com a suspeita de manipulação oficial dos programas educativos. Por outro lado, a TV tem provocado, ao 
longo dos anos, muitas discussões em torno do que é a TV de qualidade. Sobre este aspecto, Arlindo Machado (2001) enumera alguns aspectos positivos sobre a TV de qualidade e fala que pode estar relacionada ao aspecto tecnológico de produção de imagem, fotografia, roteiro, etc, assim como o comprometimento, promoção com a diversidade e a expressão de uma sociedade plural e intercultural.

O MEC conta hoje com uma ampliação do programa TV Escola, que é o Projeto DVD Escola, criado em 2004, cujo foco é garantir eqüidade do padrão de qualidade da educação básica no Brasil. O projeto sinaliza, também, o compromisso com a atualização tecnológica e democratização da TV Escola, uma vez que o acervo alcançará as escolas públicas ainda não atendidas pela transmissão do programa com o uso do DVD.

A Informática educativa é efetivada no Brasil no contexto da redemocratização, a chamada Nova República. Porém, a divulgação dessa idéia surge nos anos 70 e, de acordo com Raquel Moraes (2003), tal inserção teve um caráter intervencionista e estratégico, ligados aos interesses militares. A autora justifica que, a partir do projeto "Brasil, Grande, Potência", pós-64, surge interesse de capacitação nos setores da informática e da microeletrônica, que se tornam componentes importantes no maquinário de guerra (avião, foguete, telecomunicações, etc), reinventando um "novo ciclo de acumulação de capital e poder mundial" (MORAES, 2003, p. 16). Neste sentido, a capacitação de recursos humanos passa a ser uma necessidade neste setor e explica o sentido da informática educativa. No final dos anos 60, algumas universidades e institutos militares, como o Instituto de Tecnologia da Aeronáutica (ITA), já formavam engenheiros com treinamento em eletrônica.

Por outro lado, a aceitação de desenvolvimento de uma indústria nacional de computadores e quadro técnico surge da necessidade das forças armadas desenvolverem estratégias de 
controle e manutenção de material bélico, porque o país dependia da tecnologia estrangeira e não tinha controle industrial.

Ainda de acordo com a autora, o primeiro Programa Nacional de Treinamento em Computação (PNTC), associado à implantação de cursos universitários de graduação e pós-graduação, ligados à informática, surge, por volta dos anos 70. Considerado pela autora o primeiro programa nacional brasileiro, e não o de 1981, como registram as informações do MEC. "Ora, isso é contraditório, uma vez que o próprio MEC já se fazia representar na década de 70 na Coordenação de Assessoria ao Processamento Eletrônico (CAPRE), a qual elaborou o referido programa" (MORAES, 2003, p. 27).

Grande parte das experiências pioneiras em informática educativa surge dos projetos que foram oferecidos na modalidade presencial, por exemplo: Educom - Projeto Brasileiro de Informática na Educação-, de 1984, que teve como base projetos desenvolvidos por cinco universidades brasileiras (UNICAMP, UFMG, UFPe, UFRGS, UFRJ), vinculados à Presidência da República e ao Conselho de Segurança Nacional. O projeto visava à análise da viabilidade de se informatizar o ensino brasileiro, testar diferentes linguagens de computador, adaptar a informática aos valores nacionais e desenvolver experiências com o uso de diversos programas com alunos.

O primeiro programa de informática educativa da Secretaria de Ensino a Distância foi o Programa Nacional de Informática na Educação (Prolnfo), criado pela Portaria no 522, de 9 de abril de 1997, pelo Ministério da Educação, como objetivo de promover o uso pedagógico da informática na rede pública de ensino fundamental e médio, como ferramenta de apoio ao processo de ensino-aprendizagem. De acordo com a SEED/ $M E C$, o programa funciona de forma descentralizada, sendo que em cada Unidade da Federação existe uma Coordenação Estadual do Prolnfo, cuja atribuição principal é a de introduzir o uso das tecnologias de informação e comunicação nas escolas da rede pública, além de articular as atividades desenvolvidas sob sua jurisdição, em especial as ações dos Núcleos de Tecnologia Educacional (NTEs). 
O programa que foi desenvolvido pela SEED/MEC, em parceria com os governos estaduais e alguns municípios. Conforme os dados do senso do Instituto Nacional de Estudos e Pesquisas Educacionais Anísio Teixeira (Inep), em 2006, o Prolnfo atingiu 27 Unidades da Federação, 201.657 escolas com laboratório de informática, e um total de 13.366.829 alunos beneficiados em escolas e entidades. Para garantir o uso pedagógico da máquina, os professores fazem curso de capacitação em Núcleos de Tecnologia Educacional (NTE), que foram instalados. Cabe ressaltar que apenas 30\% destes estão conectados à Internet.

Em janeiro de 2000, a Secretaria de Ensino a Distância implantou o curso Proformação. O curso é de magistério, nível médio, e foi implantado nos estados de Alagoas, Amazonas, Bahia, Maranhão e Tocantins. O curso tem dois anos de duração e destina-se aos professores que estão em regência nas quatro séries iniciais do ensino fundamental e nas classes de alfabetização das escolas públicas das regiões Norte, Nordeste e Centro-Oeste.

O Proformação conta, atualmente, com aproximadamente 20.000 cursistas matriculados no Brasil e também desenvolve projetos no Timor Leste, Príncipe e São Tomé. É um dos maiores programas de EAD do país, voltado para a formação de professores regentes do ensino fundamental, que trabalham com classe de alfabetização, séries iniciais ou Educação de Jovens e Adultos (EJA). O curso utiliza materiais impressos, vídeo-aulas e encontros presenciais. A sua meta final é o atendimento a cerca de 50000 docentes, situados em escolas das regiões abrangidas pelo Proformação. Ao final de dois anos de curso, os alunos recebem diploma de magistério.

Em dezembro de 1999, a partir de uma reunião, em Brasília, entre 18 universidades públicas brasileiras, houve o lançamento de um documento para a criação da Universidade Virtual Pública do Brasil. O movimento recebeu adesão de praticamente todas as instituições estaduais e federais, superando 50 instituições signatárias do projeto. Em abril de 2000, os Ministérios da Ciência e Tecnologia e o da Educação baixam portaria nomeando comissões de trabalho para analisar a viabilidade da criação da instituição. 
A partir deste ano de 1999, houve também grande interesse das universidades públicas e privadas em desenvolverem projetos, em parceria ou individualmente, para criação de plataformas tecnológicas, de produção de conteúdos para EAD e de definição de metodologia de trabalho em EAD. Como exemplo, a criação da Universidade Virtual Brasileira (uvb. br), em 2000, que é um consórcio de dez universidades particulares.

Todos estes projetos e estratégias políticas que visavam à melhoria da qualidade da educação brasileira foram possíveis a partir da promulgação da Lei de Diretrizes e Bases da Educação Nacional (LDB), de 20 de dezembro de 1996, que, pela primeira vez no país, estabelece a EAD para todos os níveis e modalidades de ensino. Ao promulgar a LBD, o Brasil entra no processo internacional de valorização da estratégia da educação a distância, com o crescente uso de tecnologias educacionais indutoras de melhor aproveitamento escolar.

Em 2005, a Secretaria de Ensino a Distância criou o projeto Universidade Aberta do Brasil (UAB), publicado no Diário Oficial, no 243, de 20 de dezembro de 2005. No dia 8 de junho de 2006, foi publicado o decreto no 5.800, que dispõe sobre o Sistema Universidade Aberta do Brasil (disponível em: http:// uab.capes.gov.br/index.php).

O Presidente da República, no uso da atribuição que the confere o art. 84, inciso IV, da Constituição, decreta:

Art. $1^{\circ}$ - Fica instituído o Sistema Universidade Aberta do Brasil (UAB), voltado para o desenvolvimento da modalidade de educação a distância, com a finalidade de expandir e

interiorizar a oferta de cursos e programas de educação superior no país, cujos objetivos são:

I - oferecer, prioritariamente, cursos de licenciatura e de formação inicial e continuada de professores da educação básica;

II - oferecer cursos superiores para capacitação de dirigentes, gestores e trabalhadores em educação básica dos Estados, do Distrito Federal e dos Municípios;

III - oferecer cursos superiores nas diferentes áreas do conhecimento;

Hoje, a UAB é uma realidade. As inscrições para as graduações a distâncias foram abertas, em julho de 2007, ao mesmo, 
algumas instituições de ensino superior, principalmente nas Universidades Federais, estavam realizando processos de elaboração de material didático-pedagógico para ofertar em seus cursos e os processos seletivos para professores-tutores. Como exemplo, o Instituto de Arte da Universidade de Brasília, a Universidade Federal de Goiás, em parceria com outras instituições de ensino superior, em atendimento ao Sistema Universidade Aberta do Brasil desenvolveram os Projetos Pedagógicos de Arte Visuais, Teatro e Musica, para propor cursos de licenciaturas, nos termos da Ação 6328/2005, do Ministério da Educação, para integrar-se ao sistema nacional de educação superior a distância.

Cabe ressaltar que a Universidade de Brasília (UnB) inaugura a participação das universidades brasileiras no ensino a distância, em meados da década de 70. Sousa e Nunes (2000) afirmam que a motivação para a UnB tornar-se a Universidade Aberta do Brasil foi devido ao sucesso da Open University. A UnB adquiriu os direitos de tradução e publicação dos materiais produzidos pela Universidade Aberta e abriu cursos na área de ciência política e, logo depois, cursos no Departamento de Educação foram abertos.

De acordo com os autores acima citados, vários estudos foram feitos ao longo destes anos, abordando investigações sobre a clientela, custos dos cursos, entre outros. A partir de convênio entre a Faculdade de Educação e o Ministério da Educação e do Desporto, iniciou-se o curso de Pós-Graduação (lato sensu) em Educação Continuada e a Distância, com uma segunda edição em 1977. O curso foi aberto aos profissionais de algumas secretarias estaduais de educação e do Ministério. Em 1985, o projeto de EAD foi retomado e, em 1986, um novo curso sobre a Constituição foi proposto entre outros cursos de extensão universitária. Em 1989, foi criado o Centro de Educação Aberta e Continuada a Distância (CEAD).

No desenvolvimento da educação a distância na Universidade de Brasília, destaca-se também o Instituto de Artes (IdA), que prima pela pesquisa em linguagens das mídias eletrônicas. Em 1989, o IdA criou o Laboratório de Imagem e Som (LIS), que se encontra adequadamente equipado para o desenvolvi- 
mento de projeto de pesquisa, tanto em poéticas visuais quanto em educação a distância. Este laboratório encontra-se sob a coordenação da professora Suzete Venturelli, que, além de coordenar pesquisas desenvolvidas por alunos bolsistas em iniciação científica, orienta projetos de mestrado na linha de pesquisa - Arte e Tecnologia. Para Venturelli, "o ensino das artes visuais, nessa década e provavelmente nas do terceiro milênio, compreende também a possibilidade de suprir os alunos com conhecimentos teóricos e práticos para a utilização e o desenvolvimento de métodos computacionais na pesquisa e na criação artística" (www.suzeteventurelli.ida.unb.br/lis/fapfim/ intro.html).

Dos trabalhos desenvolvidos no laboratório, destacam-se a produção dos módulos das disciplinas: Imagem Interativa, com texto de Suzete Venturelli e Mario Maciel; Linguagem da mídia impressa: escrita e visual, com texto de Suzete Venturelli, ambos em formato de hipertexto; trabalhos de orientação em animação de imagens 3D, em realidade virtual; um Museu Virtual para Arte Computacional (www.arte.unb.br/museu/ museu.htm.), criado por Maria de Fátima Burgos; o site - A Pintura de Perspectiva de Manuel da Costa Athayde, por Luiz Fernando Suffiati (www.arte.unb.br/museu/teoria/rosto.htm), entre outros.

Em 2002, alguns professores do IdA/UnB e da Secretaria de Estado de Educação do Distrito Federal (SEE/DF), com experiência em Educação a Distância, iniciaram as discussões para elaborarem um futuro curso de arte nessa modalidade. Uma Proposta de Formação Continuada dos Professores de Artes Visuais por meio da utilização das tecnologias de informação e comunicação. Criaram o Curso de Pós-Graduação Arte, Educação e Tecnologias Contemporâneas (Arteduca- http:// arteduca.unb.br/), que está hospedado no ambiente virtual de aprendizagem da plataforma Moodle, site gerenciado no LIS / IdA. Essa idéia de criação de um curso de arte teve sua origem na dissertação de mestrado - Educação em Arte e Tecnologias Contemporâneas: Uma Proposta de Formação Continuada dos Professores de Artes Visuais por Meio da Utilização das Tecnologias de Informação e Comunicação -, defendida em 2001, 
por Sheila Campelo, sob a orientação de Suzete Venturelli.

É, atualmente, inquestionável a importância e o potencial de abrangência e funcionalidade da teleducação mundial em todos os níveis e em diversos tipos de cursos, como: Educação Básica e Educação Superior, em cursos técnicos e profissionalizantes, etc., o que demonstra que a educação mediatizada por tecnologias de comunicação e informação vem se consolidando. No Brasil, a própria Lei de Diretrizes e Bases da Educação incentiva essa modalidade de ensino, complementada pela abertura trazida pela Portaria Ministerial $n^{\circ} 2.253$ de 18/10/01, que estimulou a apresentação de inúmeros projetos por diferentes Instituições de Ensino Superior e outros órgãos, como Secretarias da Educação e o próprio MEC.

Neste sentido, as políticas públicas, afinadas às novas demandas da sociedade globalizada, têm direcionado as ações governamentais, visando a equipar as escolas com laboratórios de informática e com kits compostos por televisores, vídeos, decodificadores e antenas parabólicas, além de propor ações que possibilitam a inclusão digital da população brasileira.

Por outro lado, o mero aparelhamento das escolas e unidades de ensino não garante a qualidade de EAD, pois essa depende da adequação dos materias instrucionais às características da modalidade. Sobre a adequação do material de estudo, pode apresentar-se sob a forma de textos impressos, vídeos, programas de TV ou de rádio, CD- room, hipertextos etc., a serem veiculados por diferentes meios, para chegar ao aluno: correios, fax, telefone, rádio, televisão, internet, que são interfaces que apresentam formas diferenciadas de comunicação e interação do usuário.

O sucesso ou fracasso do programa em Educação a distância depende da otimização dos recursos tecnológicos disponíveis, formação de educadores para adequação ao uso pedagógico da tecnologia, da garantia de acesso da população envolvida, bem como da prontidão dos esquemas de manutenção, além, certamente, do entendimento de que EAD é um processo educacional centrado no aluno. 


\section{Referências}

ALVES, Lynn; NOVA, Cristiane, (orgs.). Educação a Distância: Limites e possibilidades. In: Educao a Distncia. São Paulo: Futura, 2003.

ALVES, João Roberto Moreira. Os aspectos controversos sobre a existncia de uma poltica nacional para a educa a distncia no Brasil. Disponível em: <http://www.ipae.com.br/pub/pt/cme/cme_65/index.htm>. Acesso em: 15 jan. 2007.

CHAVES, Eduardo, Tecnologia na Educao: Conceitos básicos. A EAD: Breve Histórico, 1999. Disponível em: <http://www.edutec.net/Tecnologia\%20e\%20Educacao/edconc.htm\#Ensino\%20a\%20Distância>. Acesso em: 9 jan. 2007.

COUTINHO, Laura Maria. Imagens sem fronteiras: a gênese da TV escola no Brasil. In: SANTOS, Gilberto Lacerda (org.) Tecnologia na Educao e Formao de Professores. Brasília: Editora Plano, 2003.

LOURO, Guacira Lopes. O Cinema como Pedagogia. In: LOPES, Eliana Marta T; FILHO, Lúcio Mendes de Faria; VEIGA, Cynthia Greve (orgs.). 500 anos de Educao no Brasil. 2ª ed.- Belo Horizonte: Autêntica, 2000. p. 423-446.

MACHADO, Arlindo. A Televiso Levada a Srio. 2 ${ }^{a}$ ed. - São Paulo: Editora SENAC são Paulo, 2001.

MENEZES, Claudio. Experiências em Educação a Distância na América Latina. In: Perspectiva da Educao a Distncia. Amrica Latina, Seminrio de Braslia, 1997. Secretaria de Educa a Distncia. Brasília: Ministério de Educação e do Desporto, SEED, 1998, V. 2, p. 61-78.

MORAES, Raquel de Almeida. Rumos da Informtica Educativa no Brasil. Brasília: Plano Editora, 2003.

MUNDIM, Kleber Carlos. Ensino a distância no Brasil: problemas e desafios. In: Desafios da Educa a Distncia na formao de professores. Brasília: Ministério de Educação, SEED, 2006. p. 119-126.

SADECK, José Roberto Nefta. A TV Escola do Brasil. In: 2 Anos da TV Escola. Seminrio Internacional, 1998. Brasília: Ministério da Educação, SEED, 1998.

SILVEIRA, Maria Helena. Formação do professor e educação a distância: do impresso às redes eletrônicas. In: Unirede e Seed/ MEC; FIORENTINE, Leda Maria Rangearo e CARNEIRO, Vânia Lúcia Quintão (Coords.). Mdulo1 Tecnologia e Educao: Desafios e a TV Escola. Do curso TV na Escola e os Desafios de Hoje. Brasília: editora Universidade de Brasília, 2002.

SOUSA, Maria de Fátima Guerra de e NUNES, Ivônio Barros. Fundamentos 
da Educa o a Distncia. Brasília: SESI, 2000.

SOUZA. Paulo Renato de. Dois anos de TV Escola. In: 2 Anos da TV Esco-

la. Seminrio Internacional, 1998. Brasília: Ministério da Educação, SEED, 1998. 


\section{LECI MARIA DE CASTRO AUGUSTO COSTA}

Graduada em Artes Plásticas pela UnB (1984), com especialização em Administração da Educação, Ensino de Artes Plásticas, Arte, Educação e Tecnologias Contemporâneas e em Educação a Distância. É mestre em Arte e Tecnologia pela mesma UnB (2007). Email: leciaugusto@gmail.com 